\title{
INSERÇÃO DE TECNOLOGIA NO ENSINO DE ESTRUTURAS
}

\author{
INSERTION OF TECHNOLOGY IN THE TEACHING OF STRUCTURES
}

Eveline Nunes Possignolo Costa ${ }^{1}$, José Manoel Morales Sánchez ${ }^{2}$

DOI: 10.37702/REE2236-0158.v40p462-472.2021

\begin{abstract}
RESUMO
Este trabalho apresenta a análise de uma experiência de inserção de e-learning no ensino de engenharia e arquitetura na ETH Zurique. A análise parte da referência pedagógica histórica da Instituição, que teve em seu corpo docente Carl Cullmann e Karl Wilhelm Ritter, responsáveis diretamente pelo sucesso de grandes artistas estruturais como Robert Maillart, Othmar Ammann, Isler e Menn. Criado em 1853, o Instituto Federal de Tecnologia de Zurique ficou conhecido por sintetizar a ousadia das estruturas francesas e a ciência de cálculo alemão. Culmann e Ritter basearam seus princípios de ensino em experiências de campo, viagens de estudo e ênfase em métodos visuais de análises de estruturas, representando uma nova forma de pensar a educação em engenharia estrutural pela qual os profissionais fossem capazes de interpretar novas ideias para a profissão de uma maneira prática e clara. Claudia Pedron, em experiência mais recente retoma os princípios destacados por Cullmann e Ritter, agregando uma discussão sobre o papel das tecnologias digitais no ensino de estruturas. Percebe-se que a tradição de ensino dessa instituição continua em voga, ressignificandose com o tempo ao incluir novas possibilidades abarcadas pela tecnologia, sempre com a missão de ampliar as habilidades críticas e criativas dos estudantes.
\end{abstract}

Palavras-chave: e-learning; Engenharia Civil; Arquitetura.

\begin{abstract}
This paper presents the analysis of an experience of inserting e-learning in engineering and architecture education at ETH Zurich. The analysis starts from the historical pedagogical reference of the Institution, which had in its faculty Carl Cullmann and Karl Wilhelm Ritter, directly responsible for the success of great structural artists such as Robert Maillart, Othmar Ammann, Isler and Menn. The then created in 1853, the Federal Institute of Technology in Zurich, was known for synthesizing the daring of French structures and the science of German calculus. Culmann and Ritter based their teaching principles on field experiences, field trips and an emphasis on visual methods of structural analysis, representing a new way of thinking about structural engineering education in which professionals were able to interpret new ideas for the profession. in a practical and clear way. Claudia Pedron, in a more recent experience, takes up the principles highlighted by Cullmann and Ritter, adding a discussion about the role of digital technologies in teaching structures. It is noticed that the teaching tradition of the Federal Institute of Zurich remains in vogue, giving new meaning over time to include new possibilities encompassed by technology, always with the mission to expand the critical and creative skills of students.
\end{abstract}

Keywords: e-learning; civil engineering; architecture.

\footnotetext{
${ }^{1}$ Professora efetiva do curso de Arquitetura e Urbanismo da Universidade do Estado de Mato Grosso (Unemat), doutoranda pela Faculdade de Arquitetura e Urbanismo da Universidade de Brasília (UnB), evelcost@unemat.br

2 Professor Dr. efetivo da Faculdade de Arquitetura e Urbanismo da Universidade de Brasília (UnB), sanchez.fau.unb@gmail.com.
} 


\section{INTRODUÇÃO}

O uso da tecnologia como ferramenta de ensino tem sido uma temática constante nas discussões sobre práticas pedagógicas. Apesar dos métodos básicos de educação não tenham se modificado muito nos últimos séculos, baseando-se ainda na figura do professor como centro do método de ensino, Sussekind (2015) afirma que a inserção da tecnologia, antes caracterizada de uma forma modesta pelo uso do computador para pesquisas, agora tem se mostrado como tema central em escolas de aprendizagem híbrida ou combinada.

$\mathrm{Na}$ Rocketship Education, uma rede de escolas na California (EUA), os alunos passam $3 / 4$ do dia com um professor em sala de aula e o restante usando uma plataforma online em um "Laboratório de Aprendizagem", onde um software adapta o que é ensinado às necessidades e habilidades de cada aluno (conteúdo, abordagem e ritmo). Essas escolas usam o que é conhecido como sistemas de aprendizagem "adaptativa" ou "personalizada" (SUSSEKIND, 2015).

Nas Universidades, a tecnologia tem sido adotada de forma semelhante, como recurso para aulas híbridas ou como forma de aprofundamento dos conhecimentos pelos alunos. Nesse cenário, um exemplo são as plataformas e-learning, desenvolvidas pelas próprias Universidades, como foi o caso da EdX ou Coursera, ou por instituições particulares, como Khan Academy, TED-Ed e Youtube EDU ou Udemy.

De acordo com Sussekind (2015), essas plataformas online são implantadas de maneiras diferentes. Os alunos costumam usar as plataformas para se atualizarem e se aprimorarem fora de sala de aula; alguns professores recorrem a eles como material de sala de aula e ensinam da maneira tradicional; outros usam os materiais para ensinar de maneiras diferentes, invertendo a sala de aula, por exemplo, para que os alunos assistam às aulas de rotina nessas plataformas em casa e façam os exercícios de fixação nas aulas.

Em um universo mais restrito, o da engenharia civil e arquitetura, estima-se que a inclusão da tecnologia, por meio de plataformas e-learning, possa auxiliar os alunos em maior autonomia do aprendizado, promovendo maior questionamento e liberdade aos conteúdos que até então foram ensinados de forma tradicional (com o professor como centro e a resolução de listas de exercícios). Essa crítica é trazida por Gauvreau (2005) ao analisar o ensino de engenharia estrutural na América do Norte e afirmar que, apesar de as universidades prepararem os alunos para calcular e dimensionar estruturas, não os preparam para lidarem com aspectos criativos do projeto.

No quesito criatividade, a ETH Zurique tem uma tradição por formar grandes artistas estruturais, resultado do enfoque em um ensino que valoriza a estética estrutural, sem abandonar as bases matemáticas do cálculo estrutural, apenas simplificando-o.

Dessa forma, considerando a especificidade de formação necessária ao engenheiro civil e a constante inserção da tecnologia como ferramenta de aprimoramento do ensino, esse trabalho analisará o caso de uma plataforma e-learning desenvolvida na ETH Zurique como ferramenta de auxílio para o ensino de análise estrutural para os cursos de arquitetura e engenharia civil.

Alicerçado pelo trabalho documental de Billington (1980 e 1985), primeiramente conceitua-se a tradição educacional da ETH Zurique na formação de grandes artistas estruturais, orientados por professores de ideais pedagógicos inovadores como Carl Cullmann, Karl Wilhelm Ritter. Traça-se um paralelo dessa formação inicial e sua influência na inserção da tecnologia no ensino, por meio de uma plataforma e-learning descrita por Pedron (2006).

Dessa fundamentação, apresenta-se uma análise das possibilidades que a tecnologia traz para o ensino de estruturas e como uma boa base pedagógica pode auxiliar a Instituição a caminhar para essas novas possiblidades.

\section{Entre o cálculo alemão e a ousadia francesa: a ETH Zurich}

Billington (1985) e Hu, Feng e Dai (2014) descrevem a díade da arquitetura e engenharia, em que a arquitetura documentou 
minuciosamente seus trabalhos, enquanto que pouca investigação se deu acerca das obras de arte criadas por engenheiros. Para os autores, a pouca importância que a engenharia deu à história dentro de sua formação, contribuiu para que grandes obras de engenharia fossem descritas na história da construção como associadas às grandes obras de arquitetura.

Dessa forma, Billington (1985) desenvolveu um trabalho documental defendendo uma visão de algumas estruturas como obra de arte, segundo critérios por ele estabelecidos. Nessa perspectiva, concluiu que os engenheiros devem ser ensinados sobre arte e estética, do mesmo modo que arquitetos são ensinados sobre estruturas e construção.

Assim, com base nos princípios de economia, eficiência, elegância, Billington documentou engenheiros por ele considerados artistas estruturais e suas obras revolucionárias, dentre os quais Robert Maillart, Othmar Ammann, Isler e Menn.

Para Pedron (2006), a ligação entre a conquista desses engenheiros e como eles foram ensinados é considerada como uma importante evidência do poder da educação para influenciar a prática do design estrutural.

A suíça foi o lugar em que a ousadia das estruturas francesas e a ciência de cálculo alemão foram sintetizadas. A possibilidade de abarcar as duas tradicionais nações no conhecimento de estruturas tem sido uma realidade da engenharia estrutural suíça desde 1855, quando da criação do Instituto Tecnológico Federal em Zurique (ETH Zurique). Os suíços tenderam a ser menos seguros das teorias matemáticas emergentes na engenharia e mais abertos à necessidade de demonstrações visuais de rendimento (BILLINGTON, 1980; 1985).

Carl Cullmann foi o primeiro diretor, personificando os ideais franceses e germânicos em estruturas. Isso porque, apesar de ser alemão, estudou na França, de onde trouxe uma tradição visual de análise de estrutural iniciada de forma pioneira por Gaspard Monge no século XVIII.

Em 1866, Cullmann publicou seu livro Estática Gráfica, provavelmente o livro mais influente sobre análises estruturais da época. A ideia básica por trás de seu trabalho era demonstrar o comportamento estrutural por meio de diagramas geométricos ao invés de fórmulas algébricas.

Cullmannn foi professor de Karl Wilhelm Ritter, que utilizou seus métodos gráficos para introduzir um ensino mais visual aos acadêmicos de engenharia.

Billington (1985) refere-se a Ritter como um professor que se utilizava sempre como referência de ensino, projetos já executados, buscando confrontar sempre seus alunos com o fato de que a construção de estruturas é um empreendimento estético e científico.

Além disso, pode-se considerar Ritter como o professor de engenharia estrutural mais destacado do último quarto do século XIX, parte disso por ter, como qualidade indispensável para ser o sucessor de Cullmann, a capacidade de crítica ao seu mestre.

As ideias de Ritter, como as de Culmann, se baseavam na experiência de campo, em viagens de estudos internacionais e em investigações individuais que enfatizam métodos visuais de análises. Sua metodologia de ensino incluía experiências de primeira mão com estruturas em meio natural, uma ampla variedade de imagens estruturais baseadas em resultados de construções em diferentes entornos sociais e um tipo de estudo em que o professor pudesse desenvolver uma nova abordagem para ideias antigas (BILLINGTON, 1980).

Ritter abraçou três princípios de design. $\mathrm{O}$ primeiro diz respeito à importância do cálculo e tinha como objetivo a justificação de formas mais eficientes por meio de análise simples. A partir de seu conhecimento profundo sobre comportamento físico, foi direcionando seus esforços para a simplificação do cálculo, o que para outros engenheiros, era inadmissível. Seus cálculos, mesmo que simplificados, demonstravam que a função estrutural decorre da escolha da forma e, assim sendo, descreveu seu segundo princípio.

$\mathrm{O}$ segundo princípio adverte para a responsabilidade do projetista, o qual deve incluir considerações detalhadas do processo de construção, bem como do produto acabado.

Já o terceiro princípio conecta a precisão do cálculo à qualidade da construção por meio de testes de carga em escala real. A medida final 
do sucesso estrutural é o desempenho do objeto concluído em seu ambiente natural (BILLINGTON, 1985).

Essa ideia inclui o objetivo puramente quantitativo de verificar as deflexões e deformações medidas em relação às calculadas, mas também transcende esse objetivo, pois ver a própria estrutura é, profundamente, uma experiência estética.

Para Gauvreau (2005), a abordagem pedagógica de Ritter valorizava o uso de métodos gráficos, com os quais as forças nas estruturas eram calculadas desenhando-se linhas em papel, que correspondiam à magnitude e direção do vetor representando as forças.

Esses métodos permitiam aos projetistas visualizar o fluxo de forças em uma determinada estrutura, fornecendo uma ligação direta entre o comportamento e a forma estrutural. Para além dos métodos gráficos, Ritter e, posteriormente, Lardy, também utilizaram muitos estudos e discussões críticas sobre estruturas reais, sistemas estruturais e detalhamento. A partir desses estudos, os alunos observavam o sistema estrutural dos exemplos selecionados e consideravam os aspectos estéticos do projeto em relação ao comportamento estrutural.

Isso aconteceu porque ambos os professores acreditavam que, com análise de estruturas reais, os alunos adquiriam conhecimento suficiente para ter um ponto de partida para um processo criativo de concepção de estruturas. Tais professores compreendiam a análise estrutural como uma ferramenta que atende às necessidades do projeto e não como um fim em si mesma.

Essa tradição desempenhou um papel central na carreira de Maillart, já que lhe permitiu demonstrar à profissão não somente que seus desenhos radicalmente delgados eram seguros, mas que seus métodos de análise simples eram corretos. As experiências de campo que eram propostas por Ritter, apesar de contrárias à tradição alemã, permitiu construir estruturas para as quais análises complexas ou rigorosas obscureciam o potencial do desenho (BILLINGTON, 1980).

Em termos gerais, o exemplo, principalmente de Ritter, representa uma forma de repensar a educação em engenharia estrutural considerando a necessidade de um ensino em que um dos resultados seja a formação de profissionais capazes de interpretar novas ideias para a profissão de uma maneira prática e clara. Para Billington, a tradição de Culmann-Ritter não pode ser duplicada, mas pode estimular a educação para o futuro.

O legado que Ritter deixou para seus alunos foi uma forte ênfase nos modelos como um meio de expandir as possibilidades do design, na estética como um objetivo primário do design e na forma geral como tendo precedência sobre a análise das partes (BILLINGTON, 1985).

Porém, toda essa tradição pedagógica de grandes estruturais não livrou a ETH Zurique de sofrer com os problemas atuais de formação de engenheiros. Segundo Pedron (2006), muitos alunos chegam ao final de um curso de análise estrutural sem entenderem conceitos estruturais básicos ou como as estruturas funcionam. Em algumas situações, aprendem regras básicas apresentadas pelo professor e as usam como "receita de bolo", sem considerar se isso faz sentido.

Para além da engenharia, na arquitetura os alunos não são suficientemente motivados ao estudo de estruturas. Para a autora, esses alunos são acostumados a aprender de forma visual, qualitativa e criativa.

Assim, Pedron (2006) define que os professores de arquitetura devem adotar metodologias que considerem aspectos práticos, qualitativos e visuais, a fim de entender as necessidades dos alunos e aumentar seu interesse. Para os alunos de engenharia civil, a abordagem deve incluir uma análise quantitativa. Por meio dela, os estudantes devem prever forças e tensões da seção de modo a calcular as dimensões necessárias. Para isso, eles devem aprender mais sobre estruturas complexas e diferentes tipos de análise, como estabilidade, teoria da $2^{\mathrm{a}}$ ordem, análise dinâmica ou os princípios da teoria da plasticidade e seus teoremas relacionados.

Considerando esses quesitos, o histórico de grandes professores da ETH Zurique, suas inovações pedagógicas e a necessidade de melhoria das atuais formas de ensinar 
engenheiros e arquitetos, Pedron (2006) apresenta o resultado de uma inserção da tecnologia como ferramenta de ensino a fim de ampliar as possibilidades pedagógicas.

\section{A inserção da tecnologia no ensino}

Oglesby, Yellamrayu e Flori (2005 apud PEDRON, 2006) destacam o papel da tecnologia como facilitador do processo de aprendizagem. Nesse panorama, a tecnologia permite uma interatividade e um papel ativo do aluno na aprendizagem, ao passo que possibilita simulações, animações e realidade virtual, o que ajuda a visualizar conceitos abstratos e a realizar simulações de desempenho do design. Assim, muitos professores têm tentado melhorar aprendizagem dos alunos incorporando exemplos e módulos baseados em computador, multimídia e classroom.

No ensino específico de estruturas, Pedron (2006) destaca o uso de plataformas e softwares que se baseiam em conceitos visuais, inclusão de informações referentes às cargas, localização, geometria, propriedades da seção e material. Desses, cita-se o Structural Gizmos, o Deflect, o Grips. Pode-se citar ainda, o FTOOL, que também apresenta possibilidades semelhantes.

Com base nesse destaque e em uma metodologia construtivista de ensino, foi desenvolvida um software para ser utilizado em uma plataforma e-learning, como recurso didático para os cursos de arquitetura e engenharia da ETH Zurique com o auxílio do setor de ciência da computação, denominada EasyStatics.

Essa plataforma cria para os alunos um "micro-mundo", uma representação visual do comportamento estrutural, permitindo a observação do comportamento estrutural quando da modificação dos parâmetros primários.

A plataforma não fornece diretamente as lições necessárias para um curso de análise estrutural, mas é um instrumento em que os professores podem gerar suas próprias lições, permitindo configurar livremente demonstrações de aulas e exercícios, de acordo com suas próprias preferências.
Para isso, consideram que a plataforma precisava apresentar uma interface amigável e personalização da interface gráfica do usuário, permitindo exploração, observação, reflexão e negociação, uma aprendizagem situada em problemas, além de demonstrações, exercícios e aprendizagem colaborativa.

Com recursos personalizáveis e uma interface intuitiva, no início do processo de projeto, os alunos usam a plataforma para construir a geometria da estrutura e definir adequadamente as condições de suporte. Caso não seja garantida a estabilidade, o EasyStatics desenha o mecanismo de instabilidade global de modo a permitir que os alunos reflitam sobre os graus de liberdade que precisam ser bloqueados.

Após a definição do modelo geométrico de uma estrutura com condições adequadas de suporte, as cargas são aplicadas. A cada alteração das condições de suporte, a análise é realizada novamente e os resultados são recomputados e imediatamente redesenhados. Os alunos podem entender os princípios do equilíbrio observando como as mudanças nas cargas modificam valores e direções das reações de suporte. $\mathrm{Na}$ Figura 1, uma comparação entre vigas de diferentes condições de suporte).

Figura 1 - Viga com diferentes condições de suporte
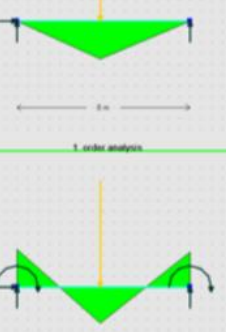
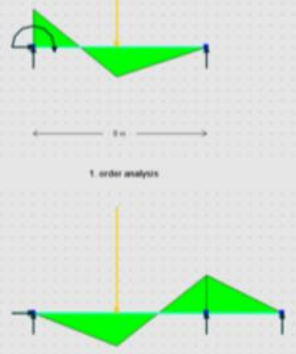

Fonte: Pedron (2006).

Depois que os professores explicam teoricamente quais são os conceitos de deslocamento, momentos, diagramas de cisalhamento e força normal, o programa pode ser utilizado para exibi-los, como mostra a Figura 2. 
Figura 2 - Representação de esforços em um arco

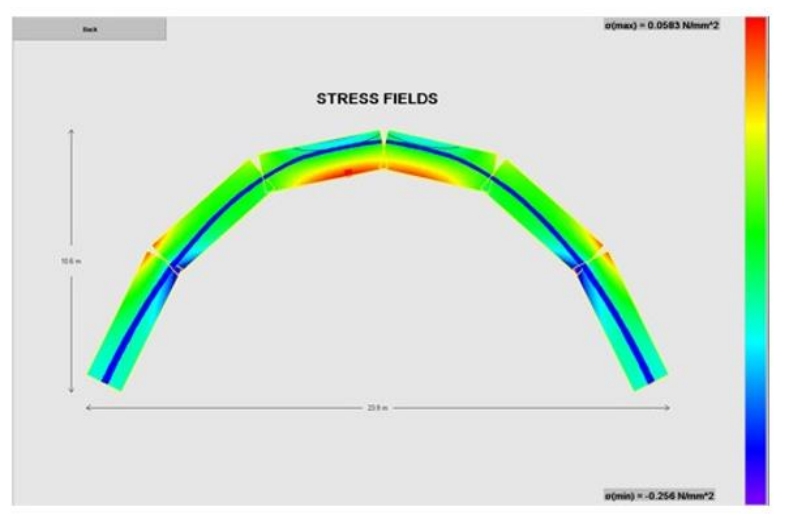

Fonte: Pedron (2006).

Além dessas funcionalidades, o professor pode atribuir um problema real a partir da exibição da imagem de uma estrutura real no fundo da tela do computador. Nessa imagem de fundo, os alunos desenham seu projeto.

A intenção de criação do EasyStatics não foi gerar um curso online completo, mas fornecer uma ferramenta de instrução adicional para enriquecer a aula presencial, de modo a ajudar os alunos a acessar informações fora da sala de aula, em qualquer lugar e a qualquer momento.

Para ser uma ferramenta de aprendizagem de projeto estrutural, o programa tem que ajudar os alunos a responderem às seguintes perguntas:

a. Quais são as deformações elásticas da estrutura causadas pelas cargas?

b. Quais são as forças de seção associadas a essas deformações?

c. Quais são as tensões causadas por essas forças?

d. As barras da estrutura pré-designadas podem suportar essas forças?

e. Quais são as influências dos efeitos da $2^{\mathrm{a}}$ ordem sobre o comportamento estrutural e quão grandes podem se tornar forças normais compressivas antes da flambagem acontecer?

f. Em que casos as cargas acidentais podem levar a efeitos dinâmicos perigosos?

g. Até onde as cargas externas podem ser aumentadas sem o colapso da estrutura e como a estrutura entraria em colapso se as cargas chegassem a esse limite?
Para responder a essas questões, são necessários modelos mecânicos que se aproximem da realidade física. O Método de Elementos Finitos (FEM) foi classificado como ideal tanto para construir tais modelos quanto para analisá-los numericamente. Todavia, apesar de usar essa teoria para os exercícios e simulações na plataforma, ela não é ensinada por ela, considerando-se que já seja de conhecimento dos alunos.

Tradicionalmente, os alunos que iniciam um curso de análise estrutural primeiro lidam com estruturas estaticamente analisadas pela teoria linear elástica de $1^{\mathrm{a}}$ ordem, sendo isso fundamental para entender todos os outros tipos de análise explicadas posteriormente. De acordo com essa teoria, considera-se um comportamento material elástico linear sob pequenas deformações, presumindo-se também que as forças normais - as quais, na configuração de referência não deformada, já podem estar presentes na estrutura - não têm influência sobre seu comportamento mecânico.

Na Figura 3, mostra-se o resultado de um dos exercícios, no qual os alunos tiveram que comparar o comportamento de diferentes pórticos sob cargas horizontais e verticais

Figura 3 - Deslocamentos em função de diferentes tipos de carga

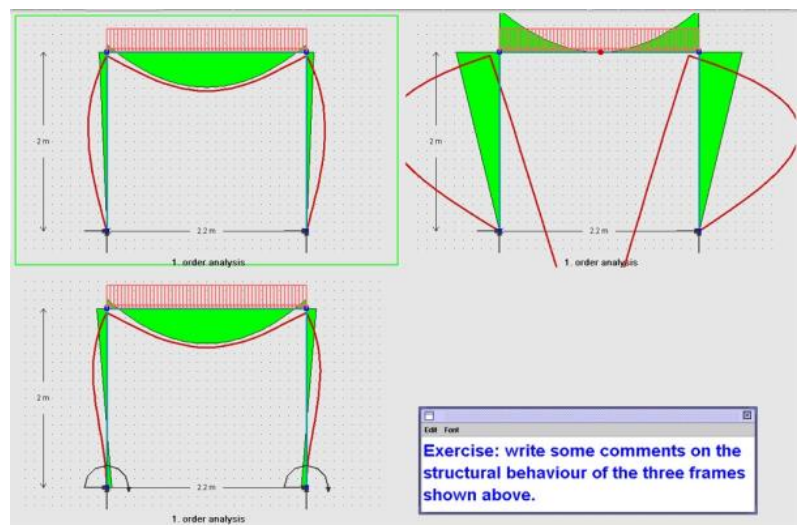

Fonte: Pedron (2006).

Em outro exercício (Figura 4) é considerado uma estrutura de Steel Frame com carga de vento e peso próprio em que os alunos podem ser solicitados a sugerir diferentes maneiras de reduzir os deslocamentos horizontais máximos. Entre as soluções, poderiam ser propostas a introdução de barras 
de contraventamento, fixação dos apoios ou aumentar a rigidez em algumas barras. A plataforma permite uma subdivisão de telas em que os alunos podem comparar todas as possibilidades, vendo imediatamente as diferenças entre os modelos.

Figura 4 - Estudo de formas de se reduzir os deslocamentos horizontais na estrutura

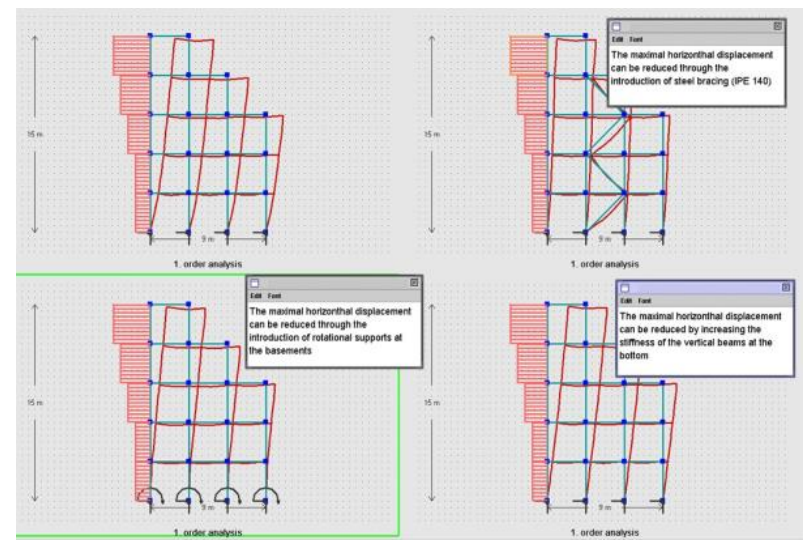

Fonte: Pedron (2006).

Em um outro exercício feito pelos professores, a partir da hipótese de treliça de Culmann (Truss-assumption - a flexão pode ser negligenciada quando as barras não são unidas por rótulas), os alunos podem testar a validade da suposição de Culmann, observando se os deslocamentos e as forças normais mudam consideravelmente quando o sistema é modelado como um pórtico ao invés de treliça e se o peso próprio for considerado por meio de cargas distribuídas ao invés de cargas nodais concentradas apenas.

A Figura 5 mostra a comparação de deslocamentos e distribuições de forças normais, primeiro no caso da estrutura considerada como uma treliça, depois como pórtico. Eles devem observar que a suposição de Culmann é, em grande parte, válida.
Figura 5 - Modelos de treliças com diferentes graus de liberdade

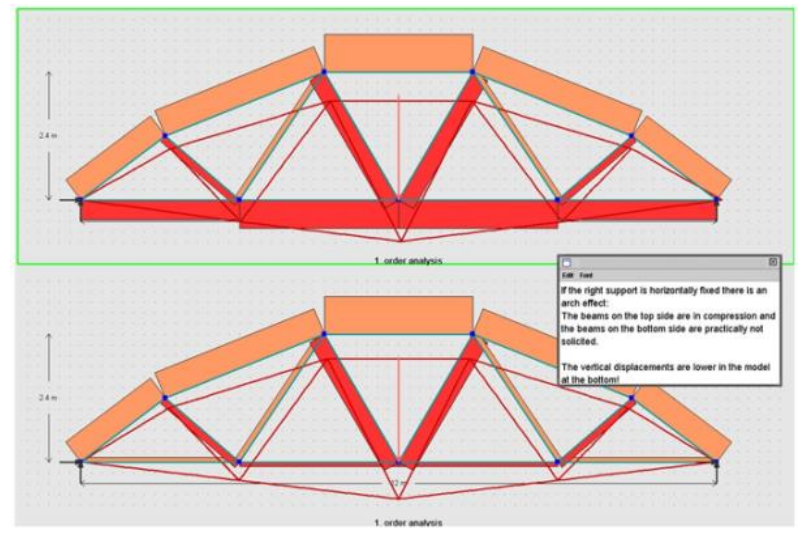

Fonte: Pedron (2006).

Além disso, a plataforma permite ainda que os alunos sejam solicitados a identificar quais barras da treliça são tracionadas e quais estão comprimidas, esboçar qualitativamente os deslocamentos, mostrar como as forças normais mudam nos banzos superior e inferior se a altura da treliça for aumentada ou diminuída, discutir o que acontece com as forças normais se ambos os suportes forem horizontalmente fixos.

Em outras simulações, os estudantes podem observar que, quanto maior é a seção transversal, menor são os deslocamentos verticais; os resultantes de tensão e compressão são encontrados perto da borda superior e inferior, respectivamente; quanto maior é a seção transversal, menores são os valores da tensão e compressão e seus resultantes.

Outra possibilidade que a plataforma permite é a de comparação de deslocamentos e momentos da estrutura analisada pela teoria da $1^{\mathrm{a}}$ e $2^{\mathrm{a}}$ ordem.

A chamada teoria da $2^{\mathrm{a}}$ ordem considera a influência no comportamento da flexão das forças normais iniciais, ou seja, de forças normais que se supõe agir sobre a estrutura em sua configuração de referência não deformada. 
Figura 6 - Comparação de deslocamentos analisados pelas teorias de $1^{\mathrm{a}}$ e $2^{\mathrm{a}}$ ordem

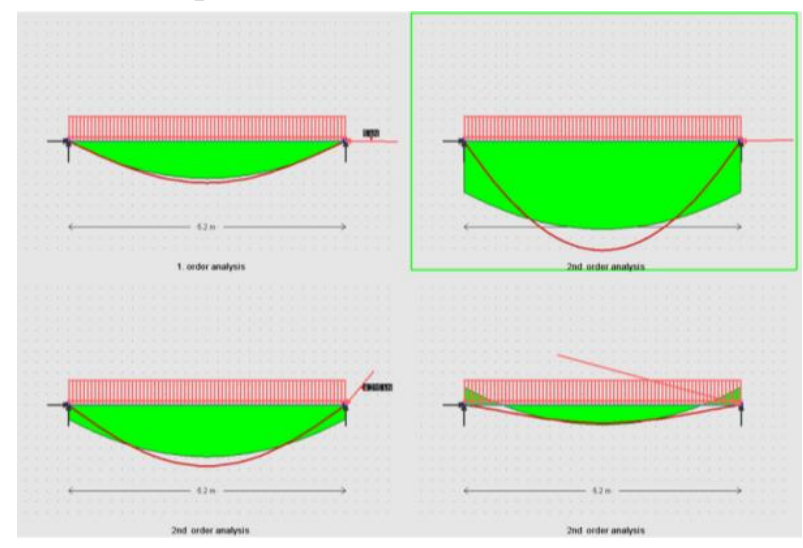

Fonte: Pedron (2006).

A plataforma do EasyStatics foi utilizada e testada nos seguintes cursos: Disciplina de Informática Estática $\left(6^{\circ}\right.$ Semestre, Engenharia Civil, ETH Zurique); uma semana de introdução em análise e design (Engenharia Civil, ETH Zurique); Curso de Estática (Engenharia Civil na Escola Técnica de Winterthur e Departamento Engenharia Civil na Universidade Técnica, Graz); Curso de projeto de estrutura de plano (Arquitetura, ETH Zurique). Pedron (2006) avalia o resultado das duas primeiras experiências dos dois primeiros cursos, os quais são apresentados também neste trabalho.

\section{Informática estática}

Curso de duas horas semanais com a participação de cerca de 40 alunos, que alterna aulas presenciais com trabalhos externos. $\mathrm{Na}$ aula, o professor explica algumas teorias que abrangem os seguintes tópicos: Teoria linear elástica de $1^{\mathrm{a}}$ e $2^{\mathrm{a}}$ e Teoria da Elasticidade.

Para entender melhor a teoria, o professor usa o EasyStatics para demonstrações, que muitas vezes contêm vários arquivos computacionais. Em cada arquivo, o professor modifica o modelo e realiza cálculos em tempo real, assim como trabalhar em um "laboratório estrutural virtual". Ele também pode mostrar a influência de uma mudança de parâmetro no comportamento estrutural, ajudando os alunos a compreender os conceitos dos diferentes tipos de análise, fazer comparações, escrever comentários e assim por diante. Os comentários são incluídos em cada arquivo, de modo a permitir que os alunos revisem posteriormente as explicações do professor. Isso ajuda os alunos a resolverem os exercícios extras atribuídos toda semana. Eles devem fazer comparações usando mais cópias da estrutura e sugerir outras soluções possíveis estimulando sua criatividade, encaminhando para o professor pela plataforma.

Por fim, os alunos são avaliados oralmente, sendo questionados sobre os conceitos teóricos ensinados com o auxílio da EasyStatics e as experiências que fizeram.

\section{Introdução em análise e design}

Todos os anos, o Departamento de Engenharia Civil da ETH Zurique organiza um curso de introdução, de uma semana, de análise estrutural e design para futuros alunos, para mostrar o que é engenharia civil. Para isso, é escolhido um projeto por meio do qual os alunos devem praticar habilidades empíricas, teóricas, escritas e orais. Tudo isso deve ser associado a algum entretenimento de modo a motivá-los.

No início do curso, o professor dá alguns conhecimentos teóricos de formação como equilíbrio, momento, forças axiais, cargas, suportes e as principais características do vidro e concreto.

Os alunos escolhem o material e usam EasyStatics para definir a geometria da ponte. Em seguida, tornam a estrutura estável introduzindo suportes, enquanto o programa informa se ocorre instabilidade. Como mais um passo, os alunos aplicam as cargas e observam as forças normais e a distribuição de momentos. Então, dependendo se os alunos trabalham com vidro ou concreto, eles tentam otimizar a geometria da estrutura considerando as diferentes características do material, enquanto deslocamentos e distribuições de estresse são mostrados em tempo real após qualquer mudança.

Na experiência descrita por Pedron (2006), os alunos tiveram que construir uma ponte de um metro de comprimento e $10 \mathrm{~cm}$ de largura feita de vidro ou concreto (Figura 7) e o EasyStatics teve que ser usado para o conceito do projeto. Em um passo final, a ponte é 
carregada até o fracasso com uma máquina de teste que mede a carga final. Os resultados desse teste são então comparados com os resultados do programa.

Figura 7 - Exemplo de modelo construído pelos alunos no curso de introdução

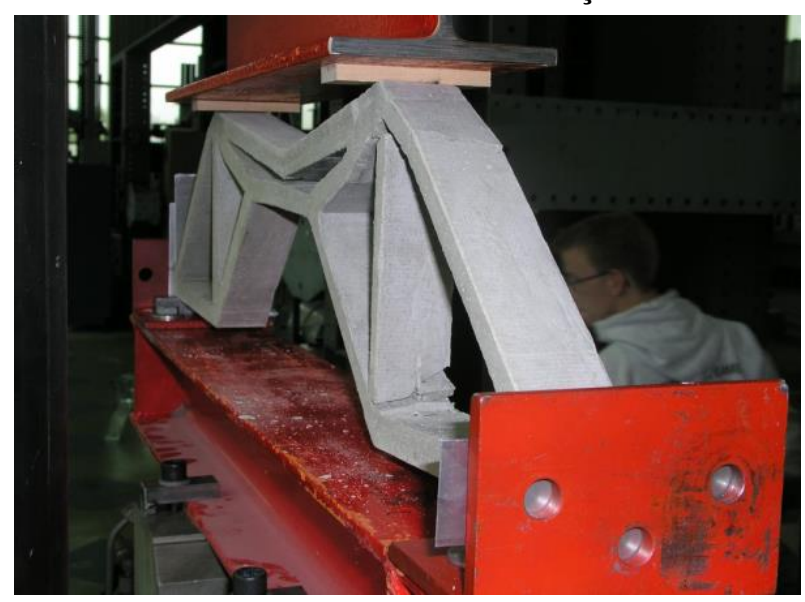

Fonte: Pedron (2006).

O grupo vencedor é aquele capaz de construir a ponte com a maior capacidade de carga.

Por fim, eles têm que preparar um pôster de modo a mostrar seu modelo, justificar suas decisões de design e comparar os resultados esperados e obtidos. Os cartazes são então apresentados oralmente durante a sessão de encerramento.

\section{CONSIDERAÇÕES}

Avaliando as questões didáticas Pedron (2006) afirma que a resposta foi geralmente positiva. Os professores pensam que, por meio do programa e suas funcionalidades (por exemplo, a representação imediata do resultado após qualquer alteração de parâmetro, a possibilidade de gerar cópias mais independentes de um modelo, a comparação entre mais modelos, os estados computacionais para apresentar diferentes situações etc.), eles podem se concentrar nos aspectos-chave do comportamento estrutural e, por meio da simulação, eles podem melhorar a atenção dos alunos e motivá-los.

Já os alunos avaliaram o programa como fácil de usar, atraente, intuitivo e uma ferramenta útil para conceitos abstratos. Eles podem aprender como modelar uma estrutura física, como as forças de seção influenciam a geometria do modelo e as propriedades da seção e melhorar sua compreensão qualitativa e descobrir, por exemplo, como as forças de seção são diagramas, verificando suas suposições com os resultados do programa.

Então, graças à fácil geração de alternativas estruturais e a possibilidade de compará-las considerando vantagens e desvantagens, eles podem experimentar o que realmente significa ser um projetista de estruturas. Além disso, particularmente no curso introdutório, eles aprendem a trabalhar em grupo, a discutir decisões, a interpretar criticamente os resultados do computador e apresentar e justificar suas ideias.

Por fim, a autora conclui que uma plataforma de internet foi desenvolvida com o objetivo de fornecer aos alunos de engenharia civil e arquitetura ferramentas modernas para aprender design estrutural. O principal objetivo da EasyStatics não foi apenas enriquecer os cursos tradicionais de análise estrutural, mas fornecer aos alunos ferramentas que os preparem melhor para atender aos prérequisitos de sua futura profissão. Com esses pensamentos em mente, muitas funcionalidades foram implementadas a fim de torná-lo uma ferramenta adequada para aprender o design estrutural.

Ela finaliza dizendo que as ferramentas computacionais precisam sempre ser um complemento e não uma substituição do curso tradicional, devendo ser uma forma em que os alunos possam rever de forma mais eficiente os conceitos aprendidos.

\section{CONCLUSÕES}

A tradição educacional de Culmann e Ritter retorna como fundamentação pedagógica em forma de uma plataforma digital, apropriando-se da tecnologia para resolver problemas há muito conhecidos das disciplinas de análise estrutural.

Das investigações de Ritter, que enfatizavam métodos visuais e de um enfoque em que a ideia pudesse surgir do desenho, o EasyStatics permite a professores e alunos, simulações do comportamento estrutural mais visuais, criando o que foi referenciado por 
Pedron como um minimundo, uma estratégia positivista de ensino que busca situar o aluno em uma problemática real e levá-lo a produzir soluções para essas.

Além disso, o EasyStatics permite uma forma de ensino híbrido, ao que os alunos testam as possibilidades de suas estruturas na plataforma e depois realizam testes em modelos reais, associando-se essa prática ao que era defendido por Ritter como experiência em primeira mão.

Assim, a tecnologia atua como uma complementação à aula tradicional e, na experiência da ETH Zurique, não chegou para substituir o legado de Culmann e Ritter, mas para complementá-lo. Os modelos gráficos desenvolvidos por Ritter antigamente desenhados à mão e nos quais despendia-se algum tempo, foram complementados pela plataforma que simula automaticamente o comportamento com base nas premissas de equilíbrio estrutural, oferendo como resultado os gráficos de esforço cortante e momento fletor. Nesse exercício, os alunos podem brincar com as possibilidades e avaliar os resultados interativamente conforme fazem as alterações na estrutura.

Pode-se concluir que as formas com as quais a tecnologia pode auxiliar as questões pedagógicas do ensino de estruturas são vastas e cabe aos professores e intuições a busca por melhores formas de promover o aprendizado de seus alunos.

\section{REFERÊNCIAS}

BILLINGTON, D. P. Wilhelm Ritter: Teacher of Maillart and Ammann. Journal of the Structural Division, ASCE, vol. 106, n. ST5, May, p. 1103-1116, 1980.

BILLINGTON, D P. The Tower and the bridge: The new art of structural Engineering. Princeton: Princeton University Press, 1985.

BUSSMANN, M. Wilhelm Ritter - von Lehrern und Schülern. Disponível em: https://blogs.ethz.ch/digitalcollections/2018/07/27/wilhelm-ritter-vonlehrern-und-schuelern/. Acesso em: ago. 2020.

GAUVREAU, P. Teaching Bridge Design in the Grand Tradition of Modern Engineering. University of Toronto: Toronto, 2005.

HU, N.; FENG, P.; DAI, G. L. Structural art: Past, present and future. Engineering Structures, v. 79, p. 407-416, 2014.

PEDRON, C. An innovative tool for teaching structural analysis and design. ETH Zurique: Zurique, 2006.

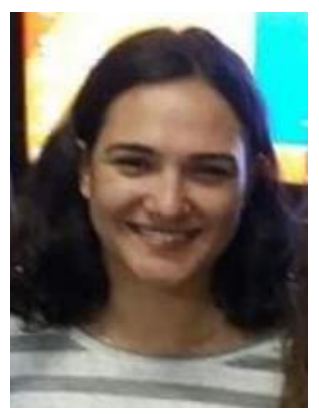

\section{DADOS BIOGRÁFICOS DOS AUTORES}

Eveline Nunes Possignolo Costa - Graduação em Arquitetura e Urbanismo pela Universidade do Estado de Mato Grosso (2011), mestrado em ciências da Engenharia Civil pela Universidade Federal de Ouro Preto (2013), professora efetiva da Universidade do Estado de Mato Grosso desde 2014 e doutoranda em Arquitetura e Urbanismo pela Universidade de Brasília desde 2019. 


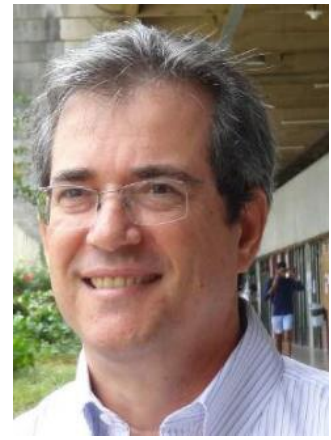

José Manoel Morales Sánchez - Graduação em Engenharia Civil pela Universidade de Brasília (1979), mestrado em Estruturas - COPPE/UFRJ Programa de Engenharia Civil pela Universidade Federal do Rio de Janeiro (1986) e doutorado em Estruturas e Construção Civil pela Universidade de Brasília (2003). Atualmente é professor associado da Faculdade de Arquitetura e Urbanismo da Universidade de Brasília. 